\title{
Retrofit Strategy in Existing Building for Implementing Energy Conservation Building Code in India
}

\author{
Manisha Yadav and Anil K. Berwal
}

\begin{abstract}
The expanding commercial building sector and urbanization in India leads to an increase in demand of energy many folds. Consequently, it is the need of the current scenario to define some regulatory regime or policy to harness the enormous potential of energy savings. Under the Energy Conservation Act 2001, the Government of India under the Bureau of Energy Efficiency launched the Energy Conservation Building Code (ECBC) on a voluntary basis. ECBC sets the standards of minimum energy performance for "large commercial buildings. These norms were for both new and existing buildings. Retrofitting of existing buildings offers noteworthy opportunities for reducing global energy consumption and greenhouse gas emissions. This paper provides a systematic approach to review the application of energy conservation building codes in existing buildings and identification of the best retrofit strategies to stimulate the implementation of ECBC in the country.
\end{abstract}

Key words - Energy Conservation Building Code (ECBC), retrofitting, barriers.

\section{INTRODUCTION}

The major factor which is responsible for severe negative environmental impact is the buildings. This is usually caused by the excessive energy, resource, and power consumption, which all contribute to greenhouse gas emissions [1]. The Energy Statistics 2013 by India's National Statistical Organization (NSO) presents more than $57 \%$ utilization of total energy consumption as electricity during 2011-12 in India, and around $40 \%$ of that electricity is utilized by the building sector already. This is expected to increase to 76 per cent by 2040. A large amount of increase in the electricity demand will come from the residential sector in India [2]. Endorsing energy efficient building practices may reduce adverse environmental impacts and enhance economic growth and social prosperity [1].

Worldwide operation and construction of buildings share an enormous proportion of total energy end-use [3]. But existing buildings consume a large amount of energy in the building sector, while the reinstatement rate of existing buildings by the new ones is $1.0-3.0 \%$ per annum only [4]. Therefore, for a sustainable future and healthy environment expeditious improvement of energy efficiency in existing buildings is prerequisite [5].

For the last decade, many momentous efforts by various governments and international organizations have been taken to improve the energy efficiency of existing buildings. The

Submitted on July 19, 2021.

Published on August 20, 2021.

Manisha Yadav, Deenbandhu Chhotu Ram University of Science and Technology, Murthal (Sonipat) India.

(e-mail: manishasmilex@ gmail.com) federal government of the United States provides evident financial help to support existing building retrofit. Under the Commercial Building Disclosure (CBD) programme (effective from 1st November 2010) by Australian Government, the owners of huge commercial offices were required to provide energy efficiency information to their potential buyers or lessees [6]. Around $\$ 8$ million were invested by the government in Queensland to reconstruct all the government buildings to enhance the energy efficiency using their 2009-2010 state budgets [7]. The UK government made a commitment, in 2010, to upgrade the energy efficiency of 7.0 million British homes by 2020 to reduce the carbon emissions by 29\% [8]. The International Energy Agency (IEA) has launched a set of Annex projects to boost the concept of energy efficiency for existing buildings, such as: Annex 46-Holistic assessment toolkit on energy efficient retrofit measures for government buildings; Annex 50 Prefabricated systems for low energy renovation of residential buildings; Annex 55 - Reliability of energy efficient building retrofitting; and Annex 56 - Energy \& greenhouse gas optimized building renovation [4].

The gap between demand and supply in the building sector might be caused due to growing energy needs of the various countries. Such issues can be potentially resolved using the energy efficiency concept as an effective tool. In general, various important codes, standards and regulations need to be proposed for the development of buildings by various regulatory bodies [9]. If these codes and standards are effectively introduced, it can result in gigantic energy saving. The main aim of the present study is to suggest efficient energy regulations by consolidating energy saving measures in building regulations from the ubiquitous codes, standards and guidelines as adopted by various nations to accomplish higher energy efficiency and reduce energy consumption in the residential area. The effort helps in noteworthy reduction and minimization of energy demand in the building sector of India [10].

Achievement of existing building retrofit practically is being considered as one of the main challenges for decreasing the consumption of energy and greenhouse gas emissions. Also, it plays a very important role in improving the nation's energy security, minimizing exposure to energy price instability, creating new placement opportunities, social responsibility and providing more human comfort [5]. Above all these uncertainties, such as changes in climate, services, human behavior, government policy etc., affect the selection

Anil K. Berwal, Deenbandhu Chhotu Ram University of Science and Technology, Murthal (Sonipat) India.

(e-mail: anilberwal@ gmail.com) 
of retrofit technologies in a direct or indirect manner. Financial limitations, long payback periods and readiness of building owners to pay for retrofits are another challenge which causes interruptions to operations [5]. Retrofit or remodeling of existing buildings not only fulfil the functional necessities, but also considerably minimize the finances, energy consumption, occupant well-being and environmental impact. Suitable extended decisions for the retrofit and effectiveness of buildings can considerably improve its thermal performance and thus cut down the energy consumption.

To meet the current energy demand requires the advancement of a highly effective Energy-Efficient Remodeling Framework (ERF) to adopt energy saving strategies in existing buildings that focus on the project from the preliminary recognition of an energy-efficient building to its Operation and Maintenance (O\&M), focusing especially on suitable energy-saving strategies and technologies for existing buildings. The proposed ERF can help construction industry and government agencies to speed up the rate of increment in energy efficiency of remodeling building stock and reduction in energy consumption of buildings which will directly reduce carbon emissions and hence improves the nation's energy security. The ERF will facilitate the energy efficient remodeling decision making practice and will incorporate energy-efficient remodeling technologies and strategies so that it can act as a guide to building energy related remodeling incentives and policies also [1].

\section{ENERGY CONSERVATION BUILDING CODES (ECBC): INDIAN PERSPECTIVE}

The Government of India has established the Energy Conservation Act on $1^{\text {st }}$ October 2001 to meet the high energy demand of the country while lowering down its promised $\mathrm{CO}_{2}$ emission levels. The Bureau of Energy Efficiency (BEE) was also set up on $1^{\text {st }}$ March 2002. Under the provisions of the EC Act, it acts as a statutory body under the Ministry of Power. The Energy Conservation Building Code (ECBC) was developed by BEE and launched on $27^{\text {th }}$ May 2007 [11]. It was revised and relaunched on $19^{\text {th }}$ June 2017 .

The Act implements regulatory mandates for labelling and standards of electrical appliances and equipment; building codes for commercial buildings on energy conservation; and standards for high energy demanding industries for better energy consumption. The Act emphasizes the Central Govt. and the Bureau to take necessary actions to meet growing energy demand thereby facilitating energy efficiency in all sectors of the economy [11]. In June 2017, updated version of ECBC 2007 was launched by BEE, with technical support from USAID i.e., ECBC 2017. The code promotes lowcarbon growth and advancements in the building sector to cut down building energy consumption levels. It is estimated to achieve a $50 \%$ decrease in energy use by 2030 by adopting ECBC 2017 for current commercial buildings in the country [11].

\section{A. $\quad$ ECBC 2007}

On $27^{\text {th }}$ May 2007, the BEE launched the Energy Conservation Building Code (ECBC) for development of new commercial buildings. ECBC introduces minimum energy standards for commercial buildings with a connected load of $500 \mathrm{~kW}$ or contract demand of $600 \mathrm{kVA}$ and above. Code conformity is spontaneous in nature with two approaches to demonstrate conformity: Prescriptive approach and Whole Building approach. In ECBC 2007, energy performance specifications were distributed under five divisions: Building Envelope (Roofs, Walls, and Windows), Lighting (Outdoor and Indoor), Heating Ventilation and Air Conditioning (HVAC) System, Water Heating and Pumping and Electrical Systems (Transformers and Power Factor). Along with five prescriptive requirements, the code also lists compulsory requirements. The obligatory requirements must be met for both the conformity approaches. It is admissible to mention that as the code implementation is not compulsory and volunteer in nature. Only few State Governments in the country have adopted and apprised ECBC in their gazettes, thereby initiating the process of composing code compliance mandatory for commercial building stock falling under amended EC Act, 2001 [12].

\section{B. ECBC 2017}

The code is mandatory for commercial buildings or any building which has a connected load of $100 \mathrm{~kW}$ or greater or a contract demand of $120 \mathrm{kVA}$. There will be three systems:

1. ECBC compiled - The building needs to save at least $25 \%$ energy (mandatory).

2. ECBC Plus- Building need to demonstrate energy saving of $35 \%$ (voluntary).

3. Super ECBC- Building needs to demonstrate minimum energy saving of $50 \%$ (voluntary).

ECBC 2017 will translate energy savings of about 300 billion Units by 2030 and peak demand decrement of over 15 GW in a year which will be identical to disbursements of Rs 35,000 crore and 250 million tons of $\mathrm{CO}_{2}$ cutback [13]. The code provides three options for compliance:

a) Compliance with the performance requirements for each system and subsystem

b) Compliance with the performance requirement of each system but between tradeoffs between subsystems

c) Whole building level performance compliance subject to the condition that the building will save the prescribed energy levels i.e., ECBC complied, ECBC Plus, Super ECBC compliance building. It is pertinent to mention that the WWR should not exceed $40 \%$ for the whole building ECBC compliance option.

\section{BARRIERS IN IMPLEMENTING ECBC AT LOCAL LEVEL}

1) Due to its voluntary nature, ECBC gives flexibility to the State Government for the implementation of code. There is no coercion on local/state governments to endorse and enforce the code. Out of 29 states only 10 states in India make it mandatory. For the implementation of ECBC it must be mandatory like environment clearance or EIA.

2) Also, due to lack of expertise and adequate knowledge only a few architects are in a 'ready-to-adopt' state to realize the energy conservation building code. Greater number of practicing architects, engineers and consultants are unable to introduce ECBC guidelines in the building design. 
3) Energy efficient material must be selected only after life cycle cost analysis and easy availability of material at local market. Also, mostly energy-efficient materials and equipment are imported which results in the demand of high-cost mark-ups and duties.

4) One of the barriers in implementing ECBC guidelines is the lack of market forces and consciousness regarding existing opportunities, information, and technology available for energy saving of buildings.

5) Unavailability of learned tutor and trainers with specific knowledge and expertise in existing professional architectural / engineering institutions to educate students about energy efficiency aspects in a building.

6) Non-availability of academic and R\&D institutions in the country which provides technical knowledge to implement ECBC.

\section{PURPOSE OF THE STUDY}

The main aim of the study is to develop an organized approach for the retrofitting of existing buildings by applying various energy efficient parameters which can minimize the energy needs of the building by using passive architectural features. The model helps in employing cost effective, energy-efficient features and technologies in all the existing buildings by various government agencies and building associates to reduce the energy demand of our building.

It will also maintain the achievement of our goal of sustainability by decreasing energy consumption and greenhouse gas emissions in the building sector and by increasing the human comfort level. The study also emphasizes the components that have considerable effects on building retrofits projects including climate, geographical location, policies and regulations, client resources and expectations, retrofit technologies, human comfort levels and other ambivalent factors. It will be all possible by upgrading the system, applicability of possible renewable energy systems, thermal comfort of the users and by changing the behaviour of the residents towards energy saving.

\section{IDENTIFICATION OF STUDY OBJECTIVES}

Important objectives for building retrofitting to achieve energy efficiency in the building as per ECBC guidelines have been identified using literature review approach and have been validated with the help of an idea engineering workshop

- To engage international bodies, and country's government and other bodies towards promotion of energy efficient building.

- To engage policymakers for promotion of energy efficient technologies and usage in the existing buildings.

- To involve and motivate bodies such as NonGovernment Organizations (NGOs) and others for promotion of energy efficiency adoption in buildings.

- To promote R\&D activities by involving research \& development and industries.

- To import required energy efficient retrofitting techniques/measures in existing building.
- To improve efficacy lighting and HVAC systems for decreasing pay-back period.

- To harness solar energy using effectively in conjunction with other energy sources and reduce dependencies upon non-renewable energies; and helping in conserving nonrenewable energy sources.

- To achieve reduced level of pollution and therefore prevent degradation of environment (being caused by reckless use of conventional fuels $\&$ resources).

- To move towards an era of sustainable development.

\section{PHASES FOR THE IDENTIFICATION AND IMPLEMENTATION OF BUILDING RETROFITTING PROBLEM}

Building retrofit aims to study auditing and execution of most efficient and valuable retrofit technologies in attaining better energy performance whilst maintaining appropriate service levels and sufficient human comfort levels, under a given set of operating hindrances. Although buildings are liable for many environmental impacts, the fact is that they also provide important facilities for human comfort, growth, and accomplishments. Thus, it is our moral duty to design, construct, operate and decimate the building in a way to maximize social prosperity, economic development and minimize environmental degradation in the area. Retrofitting or remodeling process starts only after a detailed study of the present status or record of the existing buildings which provides information about indoor environment, living space, security and solitude needed to live comfortably. It is better and more efficient to remodel an old building if it is worn out from protracted operation to improve its outdated operating systems and structure. For example, there are many government buildings and institutes that are in very poor condition. So, it is better to retrofit them before the environment becomes worse for living and work. The possibility for energy-efficiency improvements in buildings is enormous. Also, the decision of investment in energy efficient remodeling projects is eminently doubtful due to the many technical objections involving energy efficient technologies by keeping the budget in mind [1]. Here the various building identification phases are defined which helps in the execution of the retrofit process smoothly.

\section{Step-I: Pre-retrofit survey and assessment}

$\Rightarrow$ Building owners to defines the scope of work and sets the projects targets.

$\Rightarrow$ Project team to consider and assess the condition of the current building and recognize all the possible measures for energy efficient remodeling in compliance to ECBC.

Step-II: Energy Auditing and building Performance evaluation

$\Rightarrow$ Site inspection and energy auditing to identify areas with energy wastes by analyzing building energy data.

$\Rightarrow$ To recommend cheap energy conservation measures (ECMs).

$\Rightarrow$ To analyze the possible energy saving opportunities, scope, and barriers for energy-efficient remodeling of the target building by the project team.

Step-III: Identification of suitable retrofit technology and options available 
$\Rightarrow$ Selection of appropriate retrofit strategies and technologies to achieve goal of energy efficient building.

$\Rightarrow$ Identify cost effective HVAC and lighting, and renewable energy systems.

$\Rightarrow$ Identify time and cost-effective schedule and any additional measure related to the designing and construction of building.

Step-IV: Site Implementation of energy efficient features

$\Rightarrow$ Enforcement of selected retrofit measures on-site.

$\Rightarrow$ Test and commissioning (T\&C) must be engaged to ensure that all the building service systems operate in the best possible manner.

\section{Step-V: Validation and Verification of project}

$\Rightarrow$ Standard M\&V methods [14], [15] can also be used to validate energy savings.

$\Rightarrow$ For the complete satisfaction of the building occupants and building owners a post occupancy survey is mandatory.

$\Rightarrow$ Evaluate and compare the real and predicted performance of the building operating system to make sure that the facility manager and the building's users can accommodate all the system settings conveniently and address any difficulties identified during the evaluation phase [1].

\section{DETAILED AND SYSTEMATIC APPROACH FOR RETROFIT PROJECT}

Overall retrofit process requires strategic planning, major and minor retrofit activities. The approach was cultivated based upon the previously mentioned retrofit classes and important retrofit elements in concern. Here, a systematic process is defined with the help of a flow chart for retrofitting any building in compliance with ECBC. The whole procedure is classified into three stages: Pre-retrofit, Retrofit and Postretrofit. Fig. shows a systematic approach starting from the survey to identify, verify and implement the best retrofit technologies and measures in an orderly manner for retrofitting of an existing building. The mentioned approach could be used for any type of ECBC compliance building. Regular monitoring and client review are needed at regular intervals to make sure that the systems continue to operate in an efficient manner.

\section{A. Pre-Retrofit Stages}

\section{1) Energy Auditing and Planning}

Retrofitting of any building requires proper planning by considering all possible factors in mind. Any construction weather new or existing requires pre-retrofit survey. Surveys should be carried out for strategic planning and proper execution of the defined models/tools such as:

* Conduct energy audits to recognize the present status of the building and to mark the areas where energy saving potential is available and study the building performance assessment.

* It also helps in better understanding of building services and its energy performance. The retrofit possibilities can be acknowledged based on information gathered during the energy survey and auditing.

* Target energy saving retrofit measures must be identified according to client need and its financial feasibility. An efficient remodeling strategy improves insulation facilities, diminishes air leakages from building envelopes and improves thermal recovery from ventilation air by using an efficient HVAC system, available renewable energy and energy saving lighting fixtures [1].

\section{2) Building Performance Assessment}

Over the period deterioration and performance degradation of existing buildings occurs due to unexpected faults or malfunctions and inefficient operation and maintenance which leads to degradation of the overall system performance and inadmissible thermal comfort conditions. Building performance evaluation and diagnostics are widely used during building retrofit to find energy conservation opportunities and identify the problems related to system operation and energy conservation opportunities. Various building performance assessment tools have been active like BREEAM, LEED, HKBEAM, CASBEE, GBTool, Green Star, E-top, NABERS etc. Selection of a better and appropriate assessment tool is very significant and that requires proper analysis [5]. For the successful completion of retrofit projects client satisfaction is very important. A broad range of research already conducted focusing on the application and development of suitable ERF models and strategies for building performance assessment and diagnostics. This energy simulation and modeling software emerge as a very effective tool to measure the performance of different retrofit technology. Also, there are wide range of whole building energy simulation packages, such as eQUEST [12], Energy Plus, BLAST, DOE-2, ESP-r, TRNSYS, HVACSIM+ etc. that can be used to simulate the thermodynamic character and energy performance of various retrofit technologies used. For example, [16], [17] used Energy Plus to simulate the efficiency of retrofit measures for office and historical buildings, correspondingly. TRNSYS was used to examine the energy saving potential of green roofs in a nursery school in Greece [18]. DOE-2 used to measure the energy savings due to building retrofits. In the recent time Building information modeling (BIM) [19] is also used to analyze the energy evaluation of retrofit technologies used by making models of existing buildings, proposing substitutes, correlating, and analyzing building performance for these substitutes and modeling improvements [20], [21].

\section{3) Client Preferences and Satisfaction}

While working on an energy-efficient remodeling project, in the planning and design phase, it is very important to work directly with the project client while considering energy saving measures, efficiency, human health, and organizational efficacy after the energy-efficient remodeling is finished. The successful implementation of energyefficient remodeling framework projects requires close collaboration between various stakeholders like clients, architect engineering consultants and contractors. Client preferences and satisfaction is an essential key to identify which kind of retrofit technologies should be employed in a retrofit project. Also, it is advisable to do a feasibility analysis of the retrofit technologies and their possible outcome to determine whether investment in retrofits is beneficial based upon its need and finance. Client satisfaction is an extremely important index which is used to measure how much the 
services have met its client expectations. Measuring client satisfaction allows to adapt correct retrofit processes and even to correct generalized points of dissatisfaction and to promote an even better experience for the client.

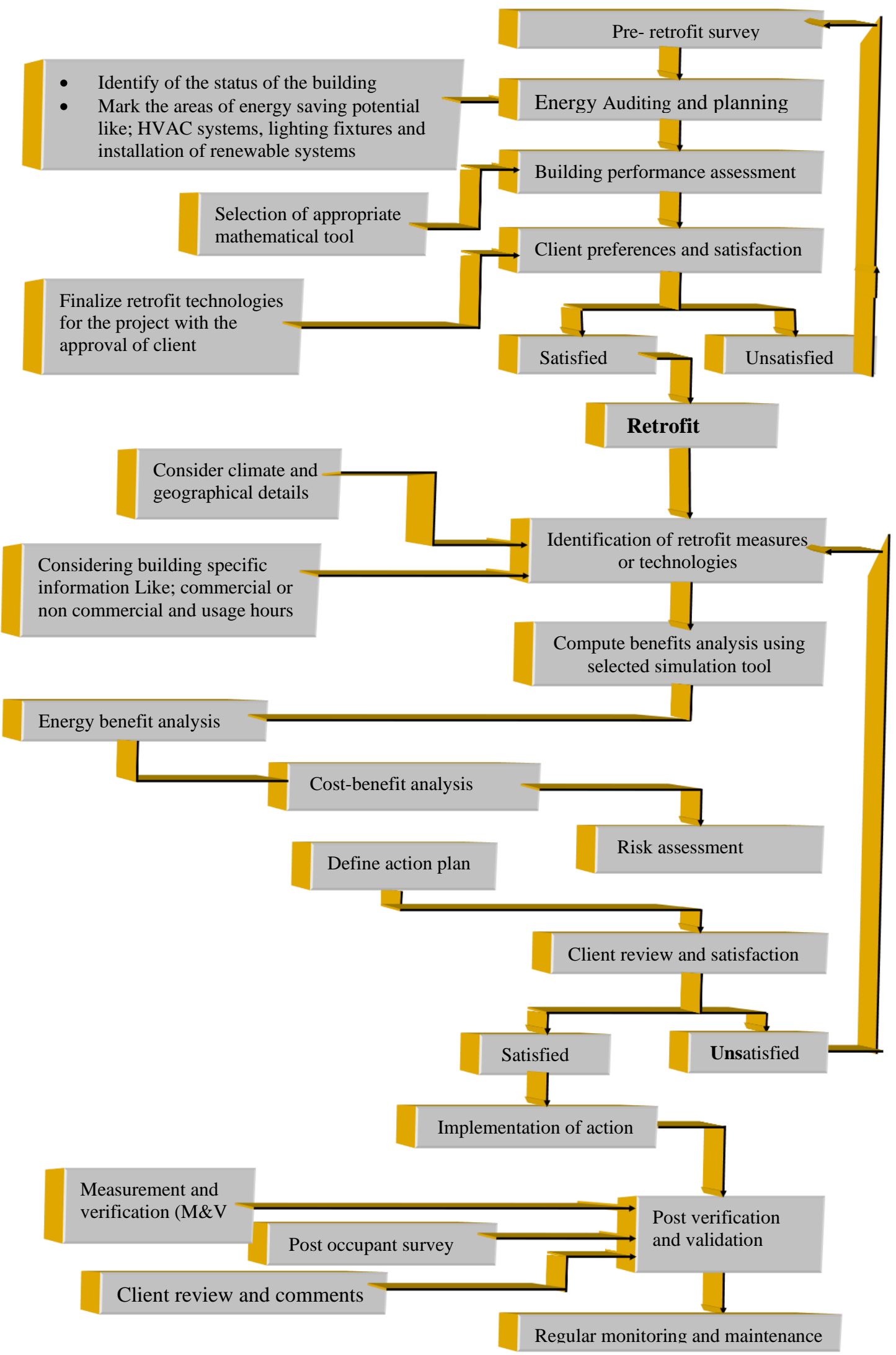

Pre-retrofit

Retrofit

Fig 1. Flow Chart for Systematic approach for retrofit strategy. 


\section{B. Retrofit Stages}

\section{1) Identification of retrofit measures or technologies}

Selection of appropriate building retrofit technologies based upon the location, use, available resources, energy demand and payback period are also very important for the successful completion of the project. To enhance building performance, the building professionals and researchers have made considerable attempts towards the application and development of many retrofit technologies and decision support tools in this regard. Also, the technologies must be selected by keeping the environment issues and client concerns in mind. The various retrofit technologies include use of renewable energy systems like solar photovoltaic (PV), wind energy, solar hot water, geothermal energy and building electrical system retrofits as alternative to yield electricity and/or thermal energy for the buildings. In the recent past, there has been a considerable interest in the use of renewable energy technologies as building retrofit measures due to the enhanced awareness towards environmental problems.

\section{1) Climate and geographic factors}

ECBC identifies five climatic zones in India and suggests different compliance for different climatic zones as the energy load requirement for each zone is different. Before retrofitting any building, it is necessary to understand its location and geographical details so that it is easy to verify the energy requirement and apply energy efficient features in that climatic zone.

\section{2) Building specific information}

Building specific information includes the type and usage of building. Some buildings are used for commercial purpose while some for residential, also some are $12 \mathrm{~h}$ working while some are $24 \mathrm{~h}$ usage buildings.

\section{2) Energy benefit analysis}

Energy benefit analysis includes both cost benefit analysis and risk assessment factors. To choose an appropriate retrofit measure is an alternate between the capital investments and possible benefits that may be obtained due to retrofitting.

\section{3) Cost analysis}

While doing a retrofit project the economic analysis aids the evaluation amid several alternative retrofit methods and provides a suggestion of whether the retrofit alternatives are beneficial and energy efficient. Various methods are available for the economic analysis of the project to measure the economic viability of building retrofit methods. The economic analysis like net present value (NPV), overall rate of return (ORR), internal rate of return (IRR), cost-benefit ratio (CBR), simple payback period (SPP) and discounted payback period (DPP) may be used to evaluate the economic viability of a retrofit measure in the project (Ma et al. 2012). The conclusion states the cost economic evaluation methodologies to allow the choice of the most profitable retrofit measure.

\section{4) Risk assessment}

Risk assessment is vital for the architects and building owners which provide an adequate degree of assurance to choose and decide the best retrofit alternative. There are several doubts involved in the building retrofit projects like percentage of energy savings estimation, energy use capacity, weather forecast, changes of energy consumption patterns, system performance degradations, etc. due to which there is high risk of investment in building retrofits. Numerous risk analysis and risk management techniques are accessible like probability-based risk assessment methods are the most used methods. The aim of retrofit is to cut building cooling and heating demand by utilizing sustainable energy efficient technologies. The heating and cooling demand of a building can also be minimized through use of efficient insulation, air tightness, windows shading, etc. efficient energy technologies may include advance control schemes, natural ventilation, heat recovery, thermal storage systems, etc.

\section{5) Action plan and execution of retrofit measures}

Now it's time to implement all the approved energy efficient strategies and features on the site in the supervision of expert members and expert laborers. The heating or cooling requirement of the target building can be minimized by using proper insulation and incorporating advanced energy efficient technologies such as shading, air tightness, efficient lighting fixtures etc. In addition to this there are some other low energy technologies features such as heat recovery, heat recovery, advance control schemes, thermal storage systems, etc.

\section{Post-retrofit Sages}

\section{1) Post verification and validation}

For the successful completion of an energy efficient retrofit project, it is important to regulate proper operation and maintenance of the retrofit building. It is necessary to establish an integrated maintenance system plan and arrange the roles of key members related to the required maintenance techniques and processes. Proper monitoring of energy efficient features also is implemented to compare or validate the pre and post retrofit energy performance. Also, reviewing existing operation and condition of current problems in relation with energy efficient remodeling strategies is important.

* Ineptitude of faculty and trainers with explicit knowledge and expertise in required architectural or engineering fields and non- availability of professional institutions to educate students based upon the energy efficiency aspects of buildings.

* Non-availability of academic and R\&D institutions in the country which provides technical knowledge to implement ECBC.

* Lack of standardization of manufacturing, fabrication, and construction of product in compliance to ECBC.

* Non- availability of testing facilities and certification of building related products such as glazing material, shading devices, insulation and construction material, fenestration products etc. to estimate the performance of building operating systems which is required in construction of ECBC compliance building.

\section{CONCLUSION AND RECOMMENDATIONS}

The main aim of the study is to promote a systematic approach for implementing ECBC in existing buildings and sustainability which help building stakeholders and government agencies, including architects, contractors, and 
owners to implement energy-saving remodeling strategies and technologies. The systematic approach developed by the study can be utilized to direct the retrofit project by suggesting step by step procedure that can be followed during the execution of projects so that energy conservation in building can be improved and hence leads to healthy environment

Initially the whole retrofit process can be divided into three stages: Pre-retrofit, Retrofit and Post-retrofit and every stage is further elaborated by proper reviewing every factor in compliance to ECBC. Also, barriers for implementing ECBC are also mentioned. The complete process must be mentioned by considering thermal comfort, client requirement, cost analysis, risk assessment and government policies in mind.

1. It's time to shift the voluntary approach of code to mandatory implementation of ECBC.

2. Need for up-gradation of current market scenario, skilled human resources, financial support.

3. Hard and fast implementation of powers of bureau like coordinating with designated consumers, designing agencies, bolstering consultancy services for energy conservation, promoting R \& D facilities, developing testing and certification procedures, and advocating ingenious financing of energy efficient projects etc.

4. More availability of ECBC compliance tools, certification of ECBC experts, master trainer, training energy auditors who can audit design specifications and investigate construction of new buildings will facilitate enforcement authorities to launch, govern and supervise ECBC implementation programs more effectively.

5. To transform energy-saving opportunities in buildings, a continuous desire to boost public policies, augment awareness and capacity building, and embrace novice trends and technologies.

\section{REFERENCES}

[1] Keonho Lee a, Bokyuoung Koo a, Borang Park a, Yong Han Ahn, "The development of an energy-efficient remodelling framework in South Korea, Habitat International, 53, 430-441. https://doi.org/10.1016/j.habitatint.2015.12.003 (2016).

[2] Power, M.O, "Energy Efficiency", Retrieved Dec 12, 2018 from govt of India, Ministry of Power. http://powermin.nic.in/en/content/energyefficiency (2012).

[3] DOE, Buildings Energy Data Book, Office of Energy Efficiency and Renewable Energy, U.S. Department of Energy, Washington, DC, USA, (2010).

[4] IEA (2011), "Energy in buildings and communities programme" Retrieved Dec 12, 2018. http://www.ecbcs.org/ (accessed on 10.12.11)

[5] Zhenjun Ma*, Paul Cooper, Daniel Daly, Laia Ledo "Existing building retrofits: Methodology and state-of-the-art" Sustainable Buildings Research Centre (SBRC), Energy and Buildings 55 (2012) 889-902 (2012).

[6] DOCC \& EE, Commercial buildings in Australia, Department of Climate Change and Energy Efficiency, http://www.climatechange.gov.au/what-you-need-to-

know/buildings/commercial.aspx (accessed on 12.12.11). Australian Government.

[7] Queensland Government, (2009), "Climate Q: Toward a Greener Queensland: Improving Energy Efficiency in Existing Government Buildings", http://www.climatechange.qld.gov.au/pdf/factsheets/8gov 1ship-b1.pdf (accessed on 10.01.12).

[8] DECC, (2012), "Warmer homes, greener homes: a strategy for household energy management, UK Department of Energy and Climate Change", http://www.decc.gov.uk/ (accessed on 10.01.12).
[9] S. Roberts, "Altering existing buildings in the UK, Energy Policy Volume 36, Issue 12, December 2008, Pages 4482-4486, https://doi.org/10.1016/j.enpol.2008.09.023 (2008).

[10] S.S.Chandel ${ }^{\mathrm{a}}$ AniketSharma ${ }^{\mathrm{b}}$, "Review of energy efficiency initiatives and regulations for residential buildings in India", Renewable and Sustainable Energy Reviews, Volume 54, February 2016, Pages 1443 1458, https://doi.org/10.1016/j.rser.2015.10.060.

[11] BEE, (2017). Retrieved Dec 12, 2018, from https://beeindia.gov.in (2017).

[12] Manisha Yadav, Anil K. Berwal, (2020) "Simulation and Analysis Of The Energy Consumption Pattern Of An Institutional Building As Per ECBC Using Equest", International Transaction Journal of Engineering, Management, \& Applied Sciences \& Technologies. 2020, Vol. 11 No.16, DOI: 10.14456/ITJEMAST.2020.316.

[13] SN Srinivas, Butchaiah Gadde, Sanjay Seth, Vittalkumar Dhage (2015), “Towards ‘Building' Energy Efficiency. Implementing Energy Efficiency in Buildings: A compendium of experiences from across the world". International Conference on Energy Efficiency inBuildings (ICEEB 2015, 17 - 18 December 2015, New Delhi).

[14] AEPCA, A Best Practice Guide to Measurement and Verification of Energy Savings, Australian Energy Performance Contracting Association, South Melbourne, Australia, 2004.

[15] EVO, International Performance Measurement \& Verification Protocol - Concepts and Options for Determining Energy and Water Savings, vol. I, Efficiency Valuation Organization, Washington, DC, USA, 2007, Available at: http://www:evo-world.org

[16] S.E. Chidiac, E.J.C. Catania, E. Morofsky, S. Foo, (2011), "Effectiveness of single and multiple energy retrofit measures on the energy consumption of office buildings", Energy 36 (8) p.p 5037 5052 .

[17] F. Ascione, F. Rossi, G.P. Vanoli, (2011), "Energy retrofit of historical buildings: theoretical and experimental investigations for the modelling of reliable performance scenarios", Energy and Buildings 43(8) p.p 1925-1936.

[18] Santamouris, C. Pavlou, P. Doukas, G. Mihalakakou, A. Synnefa, A. Hatzibiros, P. Patargias, Investigating and analysing the energy and environmental performance of an experimental green roof system installed in a nursery school building in Athens, Greece, Energy 32 (2007) 1781-1788

[19] R. Zmeureanu, (1990) Assessment of the energy savings due to the building retrofit, Building and Environment 25 p.p 95-103.

[20] L. Tobias, G. Vavaroutsos, et al., (2009) Retrofitting Office Buildings to be Green and Energy-Efficient: Optimizing Building Performance, Tenant Satisfaction, and Financial Return, Urban Land Institute (ULI), Washington, D.C.

[21] Manisha Yadav, Anil K. Berwal, (2021)“ Predicting building wall temperature in composite climate using regression models: A comparative study", Materials today: Proceedings, Volume 45, Part 6, 2021, Pages 5052-5058 https://doi.org/10.1016/j.matpr.2021.01.567.

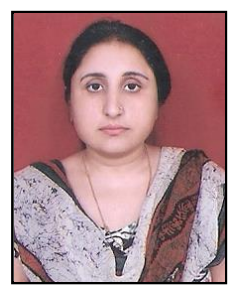

Manisha Yadav is a Ph.D. student at the Deenbandhu Chhotu Ram University of Science and Technology in Murthal, Haryana, India. She graduated with honours from the same university with an M. Tech in Energy and Environmental Studies. She had already published his work on increasing building energy efficiency, building simulation and analysis, and building thermal comfort performance in many of journals.

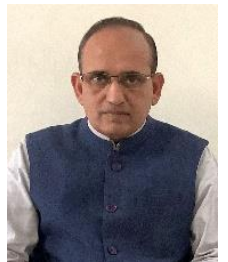

Anil K. Berwal born in October 1965 at Hisar Haryana and natural citizen of India. He has received his bachelors and master's degrees with honors in mechanical engineering and energy management, respectively. $\mathrm{He}$ is doctorate in thermal engineering and his areas of interest include Internal Combustion Engine, Refrigeration and air-conditioning, Therma Engineering, Waste Heat, Biofuel, and Solar Thermal Systems and solar photovoltaic

He has more than 30 years of experience in teaching different subjects of thermal engineering to undergraduate students of Mechanical Engineering and PG students of Energy Studies and also guided many M.Tech and PhD students. His areas of interest include Internal Combustion Engine, Thermal Engineering, Waste Heat, Bio-fuel, and Solar Thermal Systems. He has authored a book Introduction to Mechanical Engineering and published research papers in national \& international conferences and journals as well. $\mathrm{He}$ is also a certified energy auditor by BEE, GOI, He has served as member of various university bodies like Academic Council, Board of Studies etc. Apart from this, he holds membership of various professional bodies. 